\title{
Three Dimensional Analysis of Earth Pressure Balance (EPB) Shield Tunneling in Soft Bedrock
}

\author{
Chen, Shong-Loong \\ Chiu, Po-Chia
}

\author{
Department of Civil Engineering, National Taipei University of Technology
}

\begin{abstract}
There are a numbers of factors influencing the bedrock deformation caused by shield tunneling. Although many domestic and foreign scholars from the field of geotechnical engineering have conducted theoretical researches on the deformation thereof at the present time, engineering formulas and empirical statistics cannot be solely applied to complex fractured bedrock with discontinuous deformation, as complex calculation and thoughtlessness can result in an error in model adaptability and calculation applications. Thanks to the development of Plaxis 3D, a finite element method (FEM) program, we are able to simulate complicated deformation issues in a non-linear model and to analyze the stress and strain thereof. By taking the "CM01 Construction Contract Project of Taoyuan International Airport Access MRT System extended to Zongli Train Station" as an example, this study simulates the ground surface settlement deformation induced by shield tunneling and compares the longitudinal and vertical deformation curves thereof with the results of on-site monitoring equipment. The HOEK-BROWN model is also adopted to provide more precise results than the traditional Mohr-Coulomb model. In the simulation of shield tunneling, it is a must to take the shield tail grouting, shield jack thrust force and cutter head pressure into consideration by having a rather stable longitudinal settlement curve. This helps to explore ideal simulations of bedrock tunneling, to which other projects with similar conditions can be referred.
\end{abstract} FEM

Keywords-Tunneling, Rock mass, Ground Settlement,

\section{Introduction}

The decompression occurred during the shield tunneling phase not only damages the balance of rock mass, but also disturbs rock masses surrounding the shield machine due to stress. The rock masses will enter into a new balance-state, which will indirectly result in rock mass deformation and ground surface settlement. As for urban tunneling, ground surface settlement often destructs the neighboring structures and a discussion on the earth disturbance induced by Tunnel Boring Machine (hereinafter referred to as TBM) is therefore required. The earth pressure balance (hereinafter referred to as EPB) in the study case refers to controlling the advance rate of shield machine and rotation of cutter head while maintaining the stress of excavation surface. This method is to control the earth pressure of excavation chamber by adjusting the speed of TBM screw conveyor. That is, controlling the amount of excavated soil conveyed to the chamber by balancing the pressure. The movement of rocks and soil masses in TBM tunnel is a non-linear problem of material interface, including the interaction behavior between the soil mass, rock mass, materials and structure. To analyze the influence of TBM tunneling to the soil and rock masses, it is a must to evaluate the soil mass movement induced by the stress at the excavation surface of TBM. According to the study of H. Mroueh and I.Shahrour (2007) based on finite difference software FLAC3D, the longitudinal ground surface settlement along the tunnel increases as the excavation progress advances and, when the excavation length is three times of the tunnel diameter, the settlement value stops at about $0.07 \%$ of the tunnel diameter as shown in Fig. 1. However, during the excavation period, the ground surface settlement (wa) is constant, which is about $0.03 \%$ of the tunnel diameter. As indicated in Fig. 2, the TBM induced ground surface settlement in the beginning of the excavation is about $46 \%$ of the total settlement and, according to the research, the settlement occurred from the cutter head excavation process to the installation of shield tail and lining is about $77 \%$ of the total. This indicates that about $31 \%$ of the settlement is caused by the section thrust of TBM body without the lining and that the remaining $23 \%$ of settlement occurs after the assembly of segment rings, as some of the excavation-induced soil mass movements remain at site.

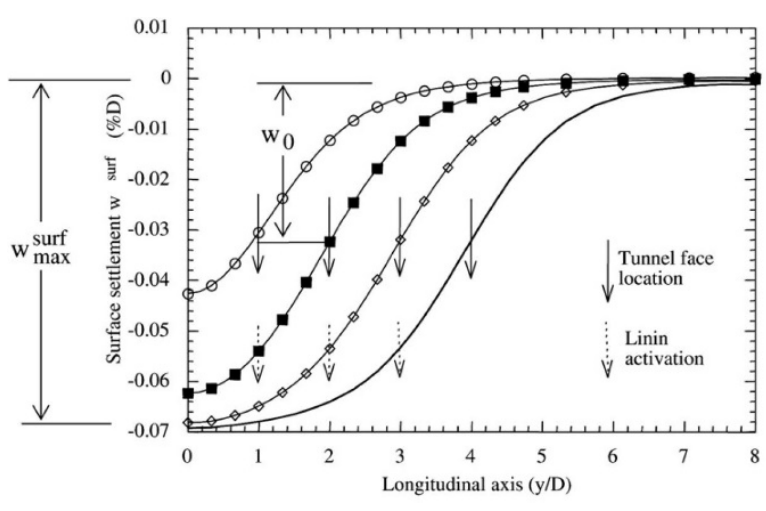

Figure 1. Changes of ground surface settlement during the tunneling period (H. Mroueh and I.Shanrour, 2007). 


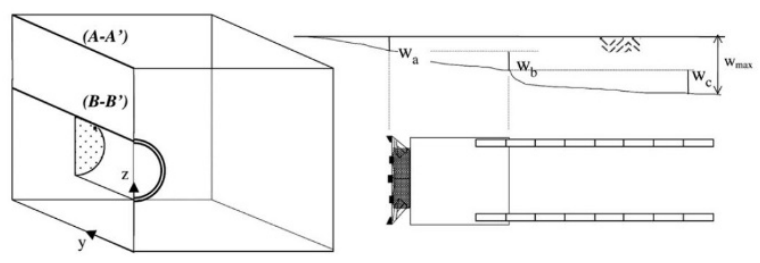

Figure 2. Ground surface settlement of the tunnel (H. Mroueh and I.Shanrour, 2007).

\section{Case Introduction}

The advantage is that it has little influence to the surrounding areas and buildings. The construction site of the study case starts from the southern side (excluded) of Airport Access MRT Station A21 (at the intersection of Zhongfeng Road and Huanbei Road). The route goes firstly southward along the Zhongfeng Road and Station A22 (at the intersection of Zungyang West Road and Zhongfeng Road); and then eastward to Zhongshan Road (passing under private houses), Zhongzhen Road (passing under the TRA Zhongli Station) and Station A23 (at the intersection of Jianxing Road, Yuanhua Underpass and Zhongbei Road), which will be a joint station with TRA Zhongli Station. Besides, a crossover will be built on Zhongzhen Road and, at the end of Station A23, a shield tunnel working shaft will be constructed to connect the Airport Access MRT Line with Taoyuan MRT Blue Line. The total length is about $2.06 \mathrm{~km}$ as shown in Fig. 3; the study section is the direct line from Station A21 to Station A22.

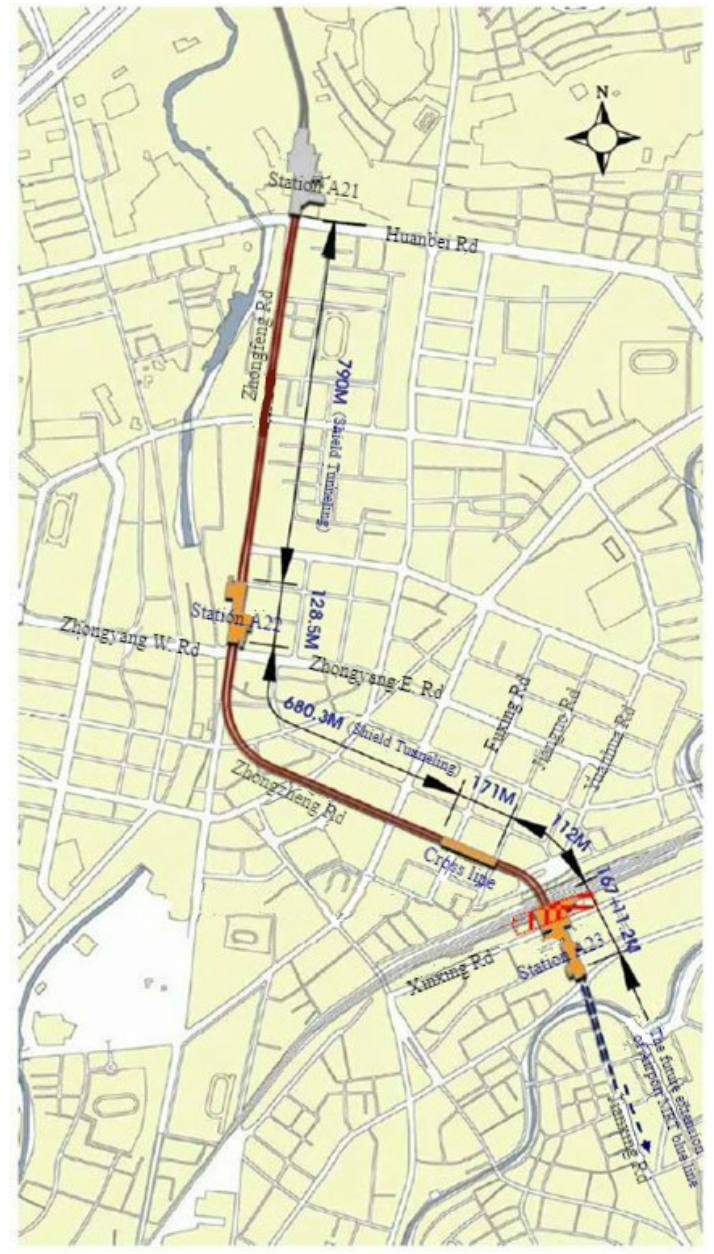

Figure 3. Schematic plan of construction site.

This shield tunneling project passes through the Zhongli plateau and requires boring in rock strata interbedded with conglomerate and sandstone. As it is extremely easy to bore in this type of poorly cemented and easy-to-soften strata, an earth pressure balance (EPB) shield machine with a total length of $13.8 \mathrm{~m}$, body length of $8 \mathrm{~m}$, diameter of $6.25 \mathrm{~m}$ and segment ring internal diameter of $5.6 \mathrm{~m}$ is therefore adopted in this project. The sectional view of the shield machine is as follows in Fig. 4.

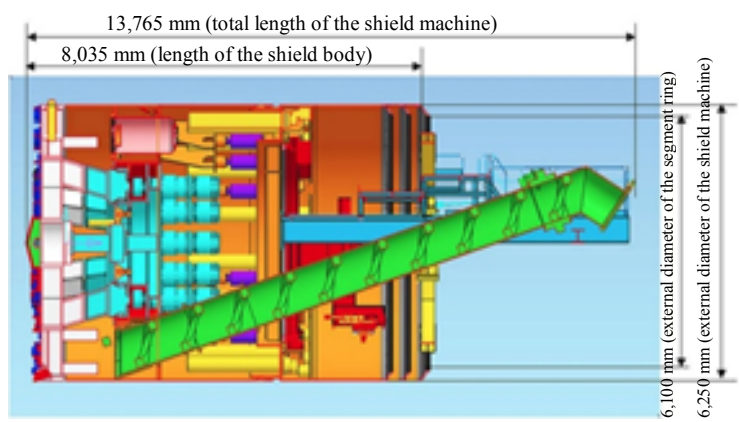

Figure 4. The shield machine structure (Freeway Bureau, Ministry of Transportation and Communications)

\section{Case Monitoring and}




\section{Management}

The causes of ground surface settlement are rather complicated, including the ground loss of the excavation surface, porosity surrounding the shield machine and shield tail gap; loss of underground water; long-term settlement caused by the dissipation of excess pore water pressure. The said factors are extremely difficult to control, especially the ground loss of shield tail gap. Following the progress of manufacturing technology and construction techniques of shield machine, not only is the ground surface settlement occurred before the shield machine reaching the excavation surface minor, but also the settlement can be analyzed when the shield machine's cutter head passes under the monitoring equipment. In practice, unless the measurements are continuous, it is not possible to know the ground surface settlement occurred when the shield machine passes through. Therefore, after the shield machine passes through, its gap with the shield tail is entirely closed. The consolidated settlement occurs during this period is known as the immediate settlement, whereas the permanent settlement occurs after the dissipation of excess pore water pressure is known as the consolidation settlement.

Shallow settlement indicator (SSI) is adopted to analyze tunneling induced ground surface settlement in the study case. This technique can verify if vertical displacement occurs to the test object during the construction.

\section{Analysis and Setting of PLAXIS}

\section{Model}

In regard to the analysis of the shield tunnel of this construction project, FEM based PLAXIS 3D is adopted to simulate the tunneling process and analyze the ground surface settlement. This software has been applied to the detailed design of Taoyuan International Airport Access MRT System and Kaohsiung MRT system. Developed and supported by Delft University of Technology (the Netherlands) and University of Stuttgart (Germany), PLAXIS is a finite element analysis software designed for earth and bedrocks. As it allows users to enter material parameters and boundary conditions in a window, it has been widely applied in civil engineering relevant numerical analysis in Europe. Besides, as tunnels have a long structure, plane stress problems shall be included in the analysis and calculation to simulate the force-bearing behavior. The analysis results include ground stress, tunnel displacement and borne stress. The nodes of structural elements are as sho

-wn in Fig. 5.

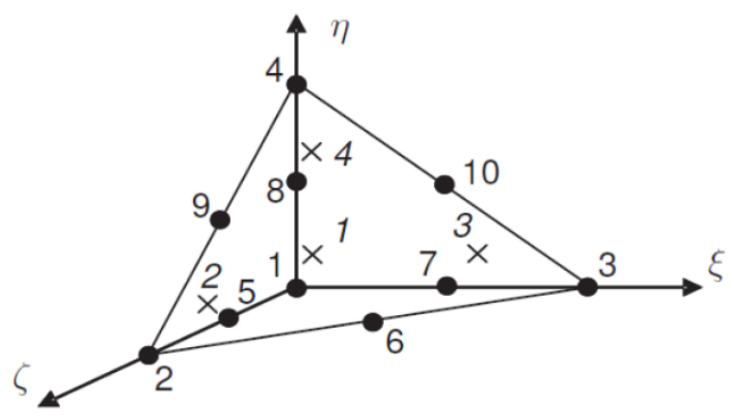

Figure 5. 3D elements of the 10 nodes of soil blocks

Shield tunnel segment rings are often made of precast concrete. During the assembly of segment rings, the shield machine stays in the same position. Only when the rings are fully installed on the site, the excavation will then continue until the excavation reaches the depth that can fit in another segment ring. Therefore, it is a must to mark off a number of construction processes in tunneling simulation. Besides, to comply with the site construction procedures, each process shall be made on the depth of single segment ring and the distance of which the shield machine shall advance. In the study case, this distance is $1 \mathrm{~m}$ and the same procedures shall be repeated in each process. Apart from comparing the numerical analysis and empirical method results, the FEM simulation results are also processed in Excel and used for essentially comparison. Besides, to simulate the influence of the mechanical excavation of the machine body on settlement, a literature review is also made to evaluate EPB TBM factors that can influence the settlement. For example, the equilibrium pressure of the cutter head, excavation of soil blocks within the machine body, the installation of segment rings, reaction force of jack and grouting pressure of shield tail shall all be taken 
into consideration in the model. The same procedures shall also be repeated in each phase to comply with the site construction conditions.

\section{Excavation Analysis and}

\section{Discussion}

\section{A. Analysis of Mechanical Excavation Simulation}

The simulations of tunneling-induced ground surface settlement in the past mainly focus on the discussion of the construction of a complete tunnel and tunneling-induced ground surface settlement. However, over the last couple of years, A. Lambrughi et al. and Micheal A Mooney et al. have adopted finite difference software FLAC to simulate TBM mechanical excavation. This proves that, when setting the TBM and TBM body simulation factors, the simulated settlement is obviously affected by the factors. Therefore, when carrying out a simulation using FEM based PLAXIS software, we also take FLAC modeling mechanical excavation factors described in the literature into consideration. In PLAXIS, we can load the pressure for a plane or line to simulate the cutter head pressure, grouting pressure and jack thrust force. Later, a model is then established and analyzed according to the excavation analysis procedures as described in the previous chapter; and the settlement amounts of simulated mechanical excavation and simulated segment ring tunnels are discussed and compared.

This study has used aforesaid simulation procedures to automatically establish the network of analyzed areas in PLAXIS; depending on the actual needs, select the refine global, refine cluster or refine line option from the Mesh menu to establish a mesh for general excavation model and mechanical excavation model of shield machine; calculate the excavation induced settlement of each stage; transfer the calculation results to MS-Excel for drawing the ground surface settlement curve and compare the curve with empirical as shown in Error! Reference source not found. and Error! Reference source not found.. The mark (w/EPB) refers to results that have encountered the influence of machine body.

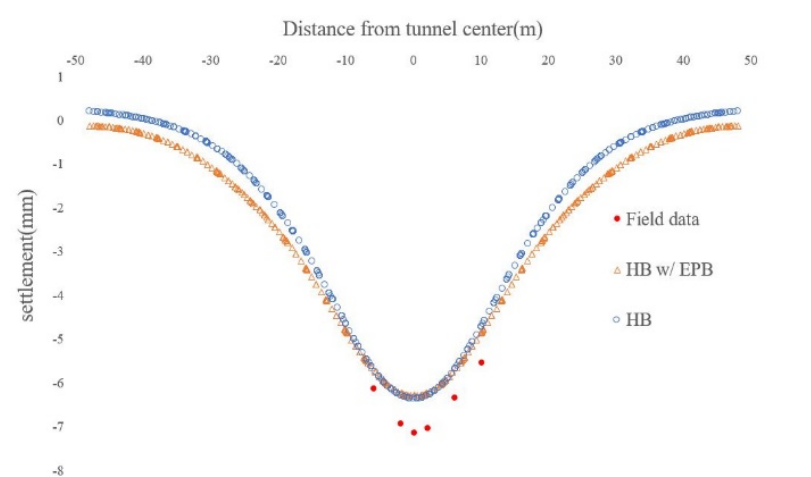

Figure 6. Simulation of the cross section settlement of TBM mechanical excavation and concrete segment tunnel.

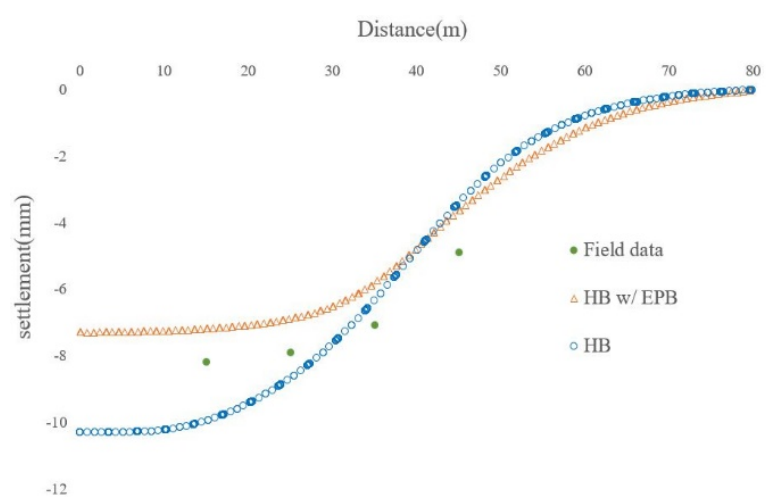

Figure 7. Simulation of the longitudinal section settlement of TBM mechanical excavation and concrete segment tunnel.

From the ground surface settlement comparison chart, the settlement of both simulated TBM mechanical excavation and simulated concrete segment tunnel reaches the maximum at the excavation cross section. Besides, despite the similarity in settlement shape, their longitudinal section settlement becomes different after leaving the shield tail section. From the study of Xiongyao Xie et al., it is known that, when the grouting process starts, the ground surface settlement will bounce back. However, the longitudinal section settlement diagram of this study indicates that, where the simulated TBM is installed, the 
grouting pressure bears the deformation induced by excavation. This proves that the application of shield tail grouting can compensate the settlement caused by the excavation of TBM.

\section{B. Comparison of Mohr-Coulomb and Hoek-Brown Models}

The Mohr-Coulomb failure criterion that is often used in ordinary numerical simulation and analysis is a linear function defined according to the shear stress of a material $\tau$; and the angle of internal friction $\phi^{\prime}$ and cohesion $c^{\prime}$ of materials are used to define the linear function thereof, namely the failure envelope. Nevertheless, in regard to model-based systems engineering in a rock environment, the PLAXIS simulation must take appropriate empirical model into consideration due to the complexity of rock mass structure. As the tunneling site of the study case is within rock strata, the PLAXIS built-in Hoek-Brown failure criterion proposed by E. Hoek and E. T. Brown in regard to the tri-axial test for a large volume of rock mass is adopted and compared with the simulated settlement results of Mohr-Coulomb model.

The study shield tunnel is located in rock strata interbedded with conglomerate and sandstone below Zongli plateau (about $11.5 \mathrm{~m}$ to $40 \mathrm{~m}$ below). The depth of tunnel center is about $23 \mathrm{~m}$ below the ground surface. As the entire tunnel passes the said strata, not only are the parameters suggested in the boring report analyzed in the simulation, but also the two patterns of ground surface settlement are compared as shown in Error! Reference source not found. and Error! Reference source not found.

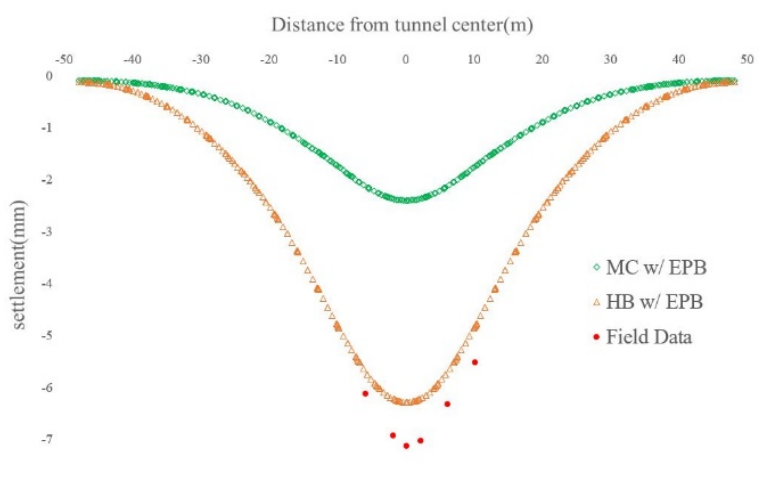

Figure 8. The analysis of the cross section settlement of Mohr-Coulomb and Hoek-Brown models.

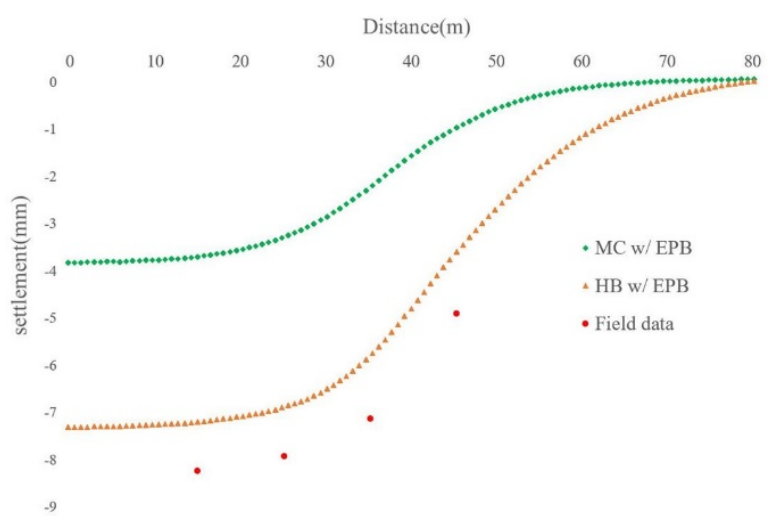

Figure 9. The analysis of the longitudinal section settlement of Mohr-Coulomb and Hoek-Brown models.

From the comparison of the ground surface settlement of these two models, it is concluded that, in regard to the rock strata that the tunnel passes through, the shear stress parameter obtained from the boring report using the Mohr-Coulomb criterion is relatively smaller than the measured settlement; the results will be lower than the current settlement. However, if Hoek-Brown model is adopted, we can better and appropriately analyze tunneling-induced deformations, which are closer to the current status.

\section{Influence of Poisson's Ratio}

Poisson's ratio refers to the ratio of transverse strain to axial strain when the material is pushed or pulled in one 
direction. It is a constant that reacts to material transverse deformation. The rock mass mechanical property refers to the ability of rock mass to resist to deformation and damage under stress, and is oriented to deformation and strength. In PLAXIS, Poisson's ratio is one of the must-have parameters as it can affect the rock mass deformation. Most of the rock mass deformation is smaller than one single rock and, because of the stress of rock mass is anisotropic, the Poisson's ratio thereof is often set as a range value. The Poisson's ratio for the sandstone layer of the study case is set between 0.05 and 0.4 , whereas most of the rock mass engineering numerical simulation has set Poisson's ratio between 0.15 and 0.3 in various literatures. This is the reason why, based on the empirical value of various literature analysis, this study has defined the Poisson's ratio at 0.15 and 0.28 and compare the settlement influence thereof. The comparison results are shown in Error! Reference source not found. to Error! Reference source not found.

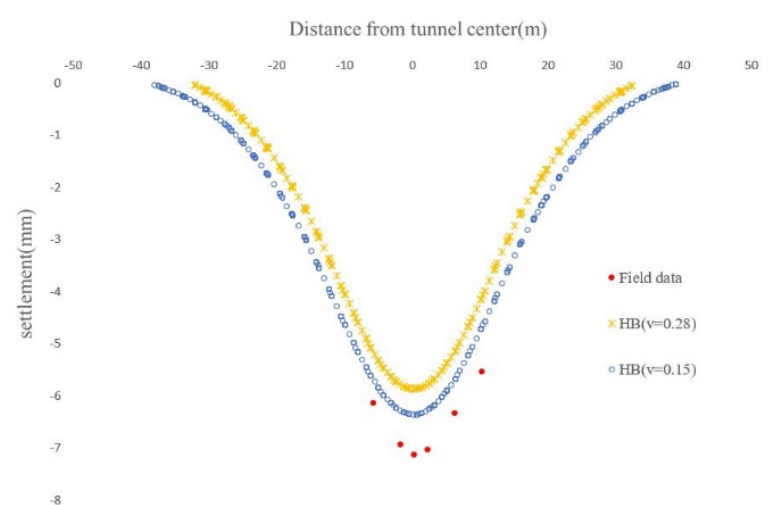

Figure 10. Influence of Poisson's ratio to the cross section settlement (simulated concrete tunnel)

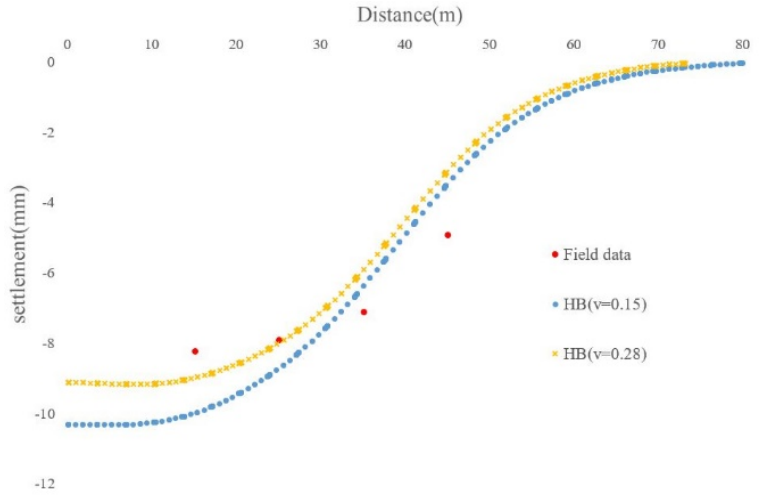

Figure 11. Influence of Poisson's ratio to the longitudinal section settlement (simulated concrete tunnel)

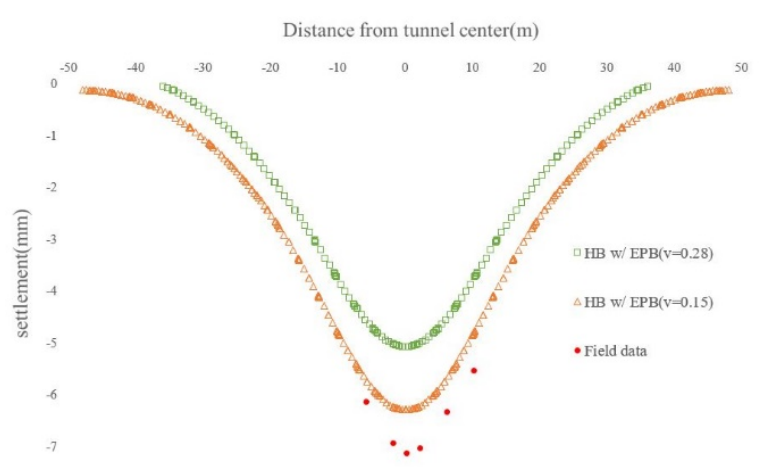

Figure 12. Influence of Poisson's ratio to the cross section settlement (simulated TBM mechanical excavation)

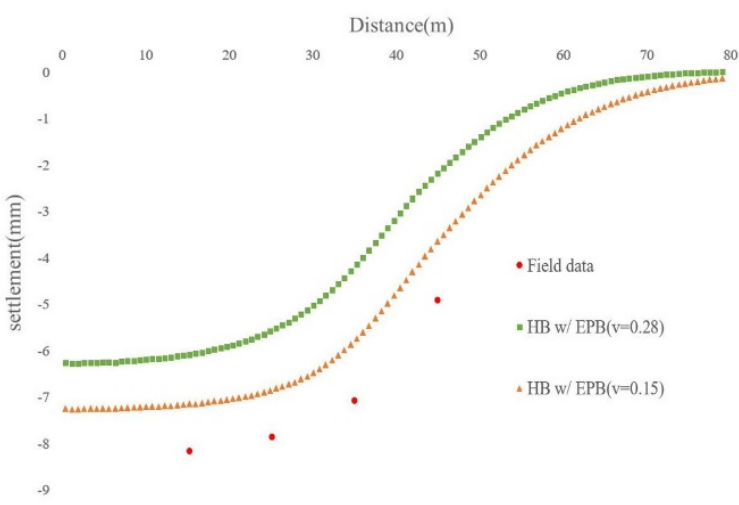

Figure 13. Influence of Poisson's ratio to the longitudinal section settlement (simulated TBM mechanical excavation)

The influence of Poisson's ratio to the settlement can be concluded from above figures: when the Poisson's ratio is 0.28 , the change of settlement curve is relatively severer, 
whereas the linear change for Poisson's ratio at 0.15 is rather steady. Considering the conglomerate and sandstone interbedded environment of the study case, the results of Poisson's ratio at 0.15 match better than that of 0.28 . Besides, the change of the Poisson's ratio of rock mass can be more obvious in the simulation of TBM mechanical excavation than that of concrete segment tunnel. In the case, the settlement of site excavation is between 0.15 and 0.28 .

\section{Influence of the Contraction Ratio of Segment Rings}

Kavvadas Michael et al. have, in regard to the presumption on the actual tunneling conditions, simulated the gradual change of TBM body and over-excavation of cutter head. The aforesaid factors will result in partial decompression in the vertical direction of tunnel (direction $\mathrm{Z}$ of the depth) and then a deformation induced settlement. PLAXIS suggests that the contraction ratio of ordinary segment ring shall be set at $0.5 \%$. However, in the numerical simulation of the study case, a settlement that is similar to that of mechanical excavation is simulated in ordinary concrete segment tunnel. Besides, when the segment rings are installed at the front end, it is a must to presume that the segment ring contraction (hereinafter referred to as $\mathrm{C}$ ) is beyond the preset value; set different contraction ratio $(\mathrm{C}=0.5 \%, 1.0 \%, 1.5 \%)$; and analyze the results to evaluate their compliance with the settlement curve of mechanical excavation. The comparison of ground surface settlement thereof is as shown in Error! Reference source not found..

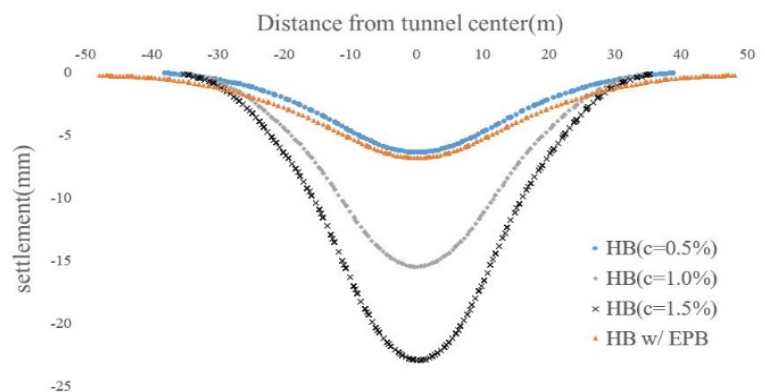

Figure 14. Influence of the change of segment ring contraction to settlement

Concrete segment tunnel can be used to increase the contraction of segment ring to simulate TBM like mechanism excavation. However, from the comparison results of settlement diagram, the increase of contraction ratio will largely affect the ground surface settlement. It is proved that using that method to run a simulation in PLAXIS is unlikely to accurately simulate the settlement results and a supplementary simulation is required to obtain results that are close to mechanical excavation and site settlement.

\section{E. Influence of Deformation inside the Tunnel}

According to the FEM analysis results of Hoek (1998), a radial deformation, which is about 0.5 to 1.5 times of the diameter on both sides of the excavation surface, occurs when the tunnel passed through a soft bedrock. This excavation effect of soft bedrock will become stable after reaching a distance from the excavation surface. This study analyzes and compares the radial deformation of tunnel crown when the excavation reaches $35 \mathrm{~m}$. That is, how the tunnel crown deformation is affected by different Poisson's ratio of the rock mass (as shown in Error! Reference source not found.) and mechanical excavation (as shown in Fig. 16).

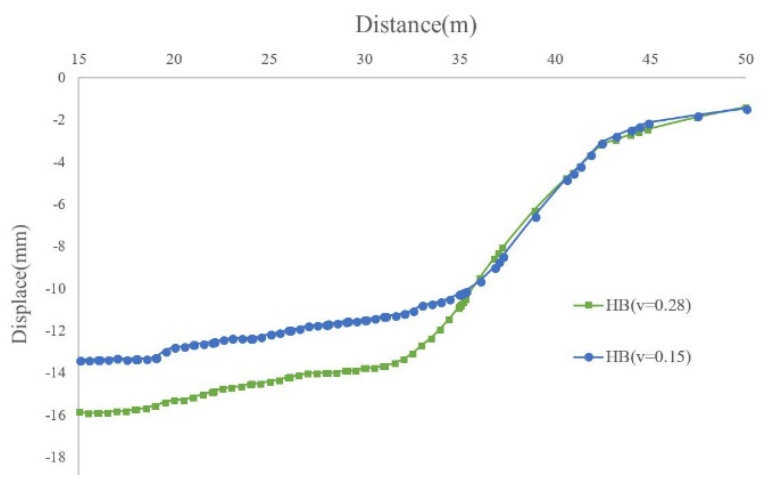

Figure 15. Influence of Poisson's ratio to the tunnel crown radial deformation. 


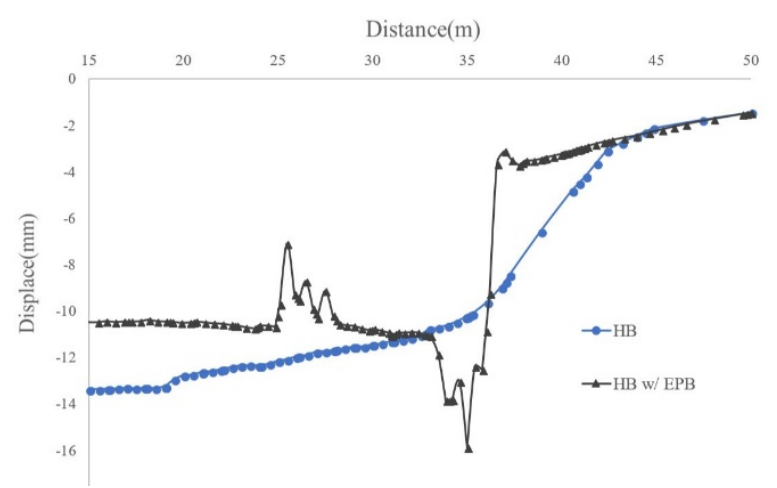

Figure 16. Radial deformation of tunnel crown.

From the influence of Poisson's ratio to the radial deformation of tunnel crown, it is known that, when the excavation surface reaches $35 \mathrm{~m}$, the excavation decompression has resulted in consistent deformation in the front (that is, from $35 \mathrm{~m}$ to $50 \mathrm{~m}$ ); as for concrete shield segment after $35 \mathrm{~m}$, the Poisson's ratio of rock mass start to have different influence on the deformation inside the tunnel. As for the influence of TBM mechanical excavation, an increment on the cutter head pressure can be observed from $27 \mathrm{~m}$ to $35 \mathrm{~m}$ of the curve of simulated TBM body. The settlement in the tunnel front $(35 \mathrm{~m}$ to $50 \mathrm{~m})$ therefore deforms little due to this pressure. However, after passing through $35 \mathrm{~m}$, the TBM body distorted in the front part (33 $\mathrm{m}$ to $35 \mathrm{~m}$ ) due to sudden decompression. The deformation gradually bounced back afterward and, after the shield tail of TBM $(27 \mathrm{~m})$ applies grouting pressure, the deformation become stable again.

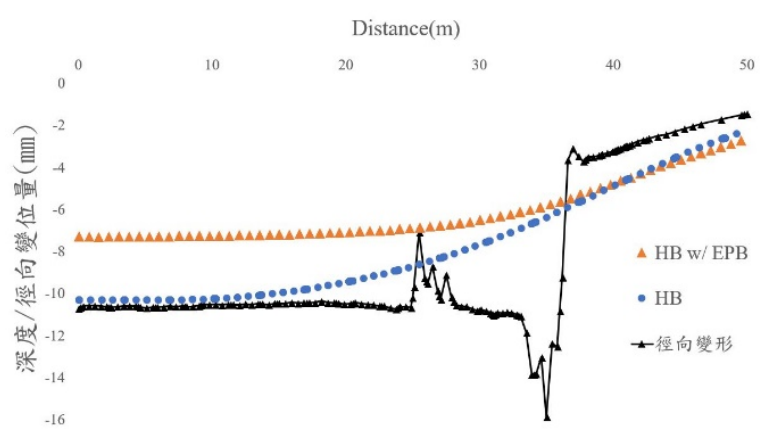

Figure 17. Comparison of radial deformation and vertical settlement.
Based on the results of Fig. 17, we have compared mechanical excavation induced radial deformation inside the tunnel and ground surface settlement in the respective location. It is obvious that the shield tail grouting pressure of simulated TBM can compensate settlement caused by the excavation. However, although a severe deformation is found inside segment ring due to the grouting pressure, the stress is evenly distributed due to the $20 \mathrm{~m}$ deep of soil covered above the tunnel and resulted in a rather smooth settlement curve on the surface ground.

\section{Conclusions and Suggestions}

With the use of FEM based PLAXIS 3D software, this study analysis the ground surface deformation induced by the tunneling process in soft bedrock. A simulation is also made based on similar geometrical location of the site, material parameters and excavation procedures, and having its results compared and verified with the site monitoring values for reasonable presumptions. Furthermore, we analyzed the influence of different parameters to simulated settlement with various factors, including the simulation of TBM mechanical excavation behavior, Poisson ratio and segment ring contraction. The objective is to discuss how these factors affect the ground surface deformation with an expectation of having these results offered to other researchers as future reference. The conclusions and suggestions of this study are as follows.

\section{A. Conclusion}

- In the analysis of rock mass materials, it is important to note that rock mass materials have rather complicated mechanical properties. Although the friction angle and cohesion parameters required by the Mohr-Coulomb model can be obtained by testing or conversions of empirical formulas, the shear strength shall not be solely used in the Mohr-Coulomb failure model as it can underestimate the settlement. The study results 
indicate that the use of Hoek-Brown model gives better settlement that is consistent with the fact.

- TBM excavation relevant factors include the cutter head pressure, jack thrust force and grouting pressure, which can all affect the settlement amount. Among them, the grouting pressure can compensate some of the settlement induced by mechanical excavation and, when a simulation is applied, it fits better the site construction configuration and operations. The simulation of TBM body also helps to predict problems derived from mechanical excavation and discover the maximum settlement in the simulation.

- Poisson's ratio is used to analysis material deformation in the study. When Poisson ratio is higher $(\mathrm{v}=0.28)$, the excavation induced rock mass deformation will become severer. When the Poisson ratio is lower $(\mathrm{v}=$ $0.15)$, the deformation is relatively flatter. As for the site settlement, the amount is between these two levels.

- Where an enhancement is made to a complete concrete segment tunnel using the segment ring contraction, the change of contraction will largely affect the simulation results. To accurately simulate similar mechanical excavation with the machine body, it is a must to have a supplementary surcharge loading system in order to have a more realistic excavation mode.

- Regarding the analysis of excavation induced radial deformation inside the tunnel, any change to the Poisson's ratio of rock mass has no impact to the deformation before the excavation. However, different Poisson's ratios can have different deformation results after the excavation. Besides, when simulating TBM mechanical excavation inside the tunnel, the radial deformation inside the tunnel is uneven at the section of TBM and the deformation become stable after leaving the shield tail. This is resulted from different loading stress of simulated machine body during the mechanical excavation. The grouting process also results in resistance in deformation and indirectly eases up ground surface deformation.

\section{B. Suggestion}

- Rock mass is a type of discontinuous nonlinear flexible material. Even rock masses of the same material can have a big difference in deformation in regard to their degree of weathering and fragmentation. Over the last decade, a number of scholars have been exploring the stress and strain behavior of rock mass, and carrying out tri-axial tests on collected samples in order to have empirical parameters. However, the rock mass theory is a newly developed field. Even if site boring data are collected, a number of questions still remain. For example, are collected data applicable to FEM analysis? Have analysis results reached purposes estimated reasonably? Can the parameter applications be objectives evaluated? All of these questions require an accumulation of more experiences in the field of engineering in order to have even more stable assessment standards.

- In the TBM simulation of this study, the grouting stress is applied in the respective location of shield tail, whereas the backfill grouting in the analysis is a gradually condensed and hardened engineering material, which can change as time progresses. For those who desire to study grouting behavior, it is suggested to apply a simulation on materials.

- The TBM in our simulation has a cylindrical body. However, shield machine can be conical with gradient segments and the linear body can affect the settlement analysis results. It is suggested that the shape of TBM can be taken into consideration in the future studies of mechanical excavation in order to find an appropriate modelling method.

- The simulation results indicate that the deformation inside the tunnel is affected by the deformation of mechanical excavation as loading cannot be used to estimate the level of deformation based on past 
experiences. However, as there is no monitoring data inside the tunnel of study site, we are unable to compare relevant results with actual excavation conditions. It is therefore suggested that those who desire to study segment ring deformation can install strain gage on segment rings and analyze the collected monitoring data.

\section{References}

[1]. A. Lambrughi, L. Medina Rodriguez, R. Castellanza,

"Development and validation of a 3D numerical model for

TBM-EPB mechanised excavations", Computers and Geotechnics, 2012, pp.97-113.

[2]. H. Mroueh and I.Shanrour, "A simplified 3D model for tunnel construction using tunnel boring machines", Tunnelling and Underground Space Technology, 2008, pp38-45.

[3]. Hoek, E., "Tunnel support in weak rock. Keynote Address, Symposium of Sedimentary Rock Engineering", Sedimentary Rock Engineering, 1998, pp.20-22.

[4]. Hoek E. and Bray JW. "Rock Slope Engineering", 3rd edition, London, 1981

[5]. Hoek E., "Reliability of Hoek-Brown Estimates of Rock Mass Properties and their Impact on Design", Rock Mechanics and Mining Sciences, 1998, pp.63-68.

[6]. Kavvadas Michael, Litsas Dimitris, Vazaios Ioannis, Fortsakis Petros, "Development of a 3D finite element model for shield EPB tunneling.", Tunnelling and Underground Space Technology, 2017, pp.22-34.

[7]. Micheal A Mooney, Jacob Grasmick, Bernadette Kenneally, Yong Fang, "The role of slurry TBM parameters on ground deformation: Field results and computational modelling", Tunnelling and Underground Space Technology, 2016, pp. $257-264$.

[8]. PLAXIS Maunual, “3D2017-Material Models Maunual”, 2017.

[9]. Hoek's corner, "Practical Rock Engineering", https://www.rocscience.com/learning/hoeks-corner 